\title{
ORGANIZATIONAL DISPOSITION AND ITS INFLUENCE ON THE ADOPTION AND DIFFUSION OF INFORMATION SYSTEMS
}

\author{
Brian O'Donovan \\ University of the Witwatersrand \\ South Africa
}

\begin{abstract}
This study proposed the concept of organizational disposition as a means to increase the understanding of the dialectic nature of the adoption and diffusion process. The concept of organizational disposition was incorporated into an integrative framework, which provided the theoretical background for two case studies. In both studies, the reactions of the users brought about a dialectic process in which the moods experienced enabled the opening up or uncovering of the reasons for resistance. The restoration of the common sense of the organization was reached through an ongoing process which integrated and reconciled the users' and implementers' dispositions into a coherent whole.
\end{abstract}

Keywords: Heidegger, disposition, adoption, diffusion, implementation, user reactions.

\section{Introduction}

Adoption can be described as the initiation, design, development and installation of an information system, and diffusion as the subsequent spread of the system through the organization and its incorporation into the organization's routines (Kwon and Zmud 1987; Prescott and Conger 1995). The terms adoption and diffusion suggest two distinct stages but this is essentially one overlapping and interacting process. This process can 
result in organizational upheaval accompanied by an unenthusiastic reception and resistance, resulting in potentially useful systems being rejected or abandoned (Wastell and Newman 1996).

There is insufficient understanding of the reasons for the frequent failure of managers to initially adopt or subsequently to diffuse information systems into organizations (Markus and Benjamin 1996). The search for these reasons can be enhanced by a better understanding of the nature of organizational change brought about by new information systems and the reactions to that change (Wastell and Newman 1996). This study seeks to increase this understanding by introducing the concept of organizational disposition to explain how reactions to the adoption and diffusion of an information system come about. The concept is also used to explore how the disruption of a proposed information system is resolved and how the organization is restored to a cohesive whole with or without the successful diffusion of the system.

The study will proceed as follows. First, a view of the nature of organizations and of change in organizations is put forward. This view is influenced by Heidegger and introduces the concept of organizational disposition. Using this concept, the strategies of implementers, the reactions of users, and the process to restore a common sense of the organization are brought together in a framework. Finally, the framework is used to explain some of the dynamics of this process using two case studies.

\section{The Nature of Organizations and of Change in Organizations}

Heidegger's exposition of Dasein addresses the primordial or essential being of the human person. The term Dasein is used by Heidegger to describe existing (Sein-being) within ( $D a$-both here and there) a world where others exist (Introna 1997, p. 27). Or more simply put, the human being as a "being" that is always already "there" (present), that is always already involved and engaged, as its constitutive essence. In Heidegger's analysis Dasein does not describe the nature of communal groups such as organizations. However, it is contended that organizations share in the nature of Dasein but in a way that can be described as a subpattern within the grand pattern that is Dasein (Haugeland 1982, p. 19).

This subpattern draws on the context in which the organization is embedded and in which there operates a generally accepted set of norms and conventions that become part of what it means to do something in that world called the organization. Heidegger uses the term Das Man (which can be translated as the anyone) to describe this set of shared norms and conventions. It refers to the impersonal and non-specific "they" in phrases such as "they said it" or "they don't like it." Each organization, in turn, establishes its own local Das Man, which enables its ongoing activity to take place with a reasonable amount of order.

This local Das Man can be referred to as the cultural structure (cf. Walsham 1993, p. 34). It incorporates culture in the customs and practices that develop over time and provide a web of collectively accepted meanings and assumptions, which becomes the frame of reference underlying the perceptions, interpretations, understandings and communications of the members (cf. Schein 1990). It also incorporates structure in the way the members undertake their day to day activities and interact accountably, guided 
and controlled by common norms, conventions and rules, and the currently accepted distributions of power.

The cultural structure underlies all organizational activities and binds and articulates those activities. These activities, in turn, require the use of objects such as tools and materials, or as Heidegger terms it, "equipment." In using "equipment," organizational members encounter others who are relevant to their use of that equipment. The interconnected network of "equipment" is thus placed within a context of activities in which others are involved. It is those others who add human purposiveness and give the organization meaning or significance. The organization is thus made up of a cohesive whole of a context of meaning or significance bound together by the cultural structure.

There are three influences on the maintenance of the cohesiveness of the organization: socialization, social networks, and conditions of work. Socialization, begins with procedures to attract and select individuals whose attitudes or values are likely to be congruent with organizational needs and continues with formal and informal training and direction (Van Maanen and Schein 1979). New members will be susceptible to clues and signs given to them by those who support and guide them in their roles and demonstrate the attitudes and values specific to the organization. These actions include ostracizing those who do not fit in or accepting those who do. Through social networks, the attitudes and values of the members are further influenced by their perceptions of the nature of other groups and organizations and the social and historical context in which the organization is embedded.

The influence of conditions of work reflects the need for a reciprocal balance between the members of the organization. This reciprocal balance is not a conscious agreement but arises from the way individuals cooperate with others to achieve their own goals and expectations. Members take on obligations in exchange for tangible benefits, such as material reward, and intangible benefits such as opportunities for advancement or a comfortable work situation (Silverman 1970, p. 178). Some members will confer power on others in order to have less responsibility and reduce uncertainty (Coombs, Knights and Willmott 1992). Others will seek responsibility in order to have power and prestige. Reciprocity is thus sustained by the acceptance of the distribution of power as well as the reciprocal commitments and entitlements that arise from membership of the organization (Gouldner 1960).

The recognition, understanding and acceptance of opportunities for mutual benefit provide the basis for the transformation of the organization. In his exposition, Heidegger puts forward four "ways of being" that presuppose and produce the shared nature of Dasein. These are Dasein's way of disclosing the world and discovering things in it (Dreyfus 1991, p. 166). If the four "ways of being" are adapted to the context of an organization, they describe how innovative ways to do things are uncovered, evaluated, find acceptance and become incorporated into the routine. The full discussions of these are beyond the scope of this paper and only the aspect of organizational disposition will be considered.

\section{Change and Organizational Disposition}

Change can be said to result from an interdependent progression of actions, reactions and interactions (Pettigrew 1987). A key aspect of this progression is the reactions of 
organizational members to change. When faced with possible changes to ongoing activities, the members have dispositions that influence whether they "accept" some or "reject" others ("accept" or "reject" does not refer to cognitive processes, as will become clear). Heidegger's "way of being" relevant to these dispositions is Befindlichkeit. Befindlichkeit has been translated as "affectedness" in the sense of a shared sensitivity to those people and things that matter. It has also been translated as "so-foundedness" in the sense of being "found" in a situation where certain possibilities are of importance (Dreyfus 1991, p. 168). It may be best described as that which we find ourselves in, when we suddenly stop to take notice (be it in a particular situation, condition, predicament, opportunity, and so forth). The important point is that we always find ourselves in something, entangled in a host of situations, predicaments, opportunities, and so forth - this is our "so-foundedness," our Befindlichkeit. In our finding ourselves in, some things matter and others do not, some ways of doing make sense and others do not. We are never merely neutrally "there." The way in which our Befindlichkeit manifests itself in our everyday dealings in the world is as mood (Stimmung). Here mood is not purely an emotive, internal, notion (such as "he is in a bad mood") but rather a particular sense or tacit awareness of our being in-ness, of finding ourselves in the world. It is that "just below the surface" sense of awareness of the importance (or not) of a particular moment (of a particular situation, condition, predicament, opportunity, and so forth) that we find ourselves in. As such, it discloses the world and its possibilities to us.

In the organizational context, Befindlichkeit will be referred to as organizational disposition. Organizational disposition is not a state of mind (despite the use of the term by the translators of Being and Time), nor is it a cultural disposition to behave (Dreyfus 1991, p. 168). It is not the additive combination of individual dispositions, but the common moods of the members which are reflected from the organizational world rather than from introspection (Dreyfus 1991, p. 174). It is a tacit awareness, which flows from being engaged in the world, of a collective "finding ourselves in" that is just there but never really there-a sort of collective sense of "being in this thing together" and a tacit awareness of what it means in terms of expectations and actions. "It comes neither from "outside" nor from "inside" but arises out of being-in-the-world, as a way of such being" (Heidegger 1962, p. (176)[136]). ${ }^{1}$

As a way of being, organizational disposition is a way of disclosing or uncovering the nature of a current situation in the cohesive whole of the organization-both the context of significant or meaningful activities and the cultural structure. Through disposition, the members have an attunement or sensibility to everyday situations. This attunement is manifested in moods which have already disclosed being-in-theorganizational-world as a whole (Heidegger 1962, p. (176)[137]). One could say that the organizational disposition is the common sense of the members in the situation. Common sense should be understood in two ways. First, common sense refers to the fact that it is a mood, a sense, of what it, the whole (the situation), is "telling" us. Second, it

' The practice of using two page numbers to reference quotations from Being and Time will be followed. The first page number in parentheses refers to the standard English translation and the second page number in brackets refers to the page in the standard German. It should be noted that many of the cited references to Heidegger and commentators on his work refer to the individual Dasein and these have been adapted to apply to organizations. 
refers to the fact that it is an everyday tacit awareness of what would be the appropriate response in this particular situation in which we find ourselves.

The members are always already surrounded by the cohesive whole of the organization and this whole matters to them as, within it, they have a capacity or ability to be. There is thus always the possibility that members will find opportunities or new ways to do things. There is also always the possibility that members will find themselves in certain moods as a result of confronting these opportunities or new ways to do things. These moods reveal how things are going for the members and whether these things matter (Dreyfus 1991, p. 172). Through these moods, organization disposition attunes the members' tacit awareness of the nature of change and "informs" them of appropriate responses to this change (Heidegger 1962, p. (172)[134]). Organization disposition is thus a way of being which affects the members' understanding of the nature of changes to activities. It is at once a sensibility, a sensitivity and a sensing - a prevailing common sense.

It is important, and hopefully clear from the above, that organizational disposition is not the culture of the organization but rather the situated attunement (sense of the whole) that flows from engaged action in the world. One may argue that it is an element of culture. However, the discourse on culture (even in Schein) has tended to turn culture into a "thing" (in the minds of the organizational actors) - to be measured, managed, and so forth. This sort of conception perpetuates the Cartesian dualism of separating cognition and action. In this sense, one could say that organizational disposition is a post-Cartesian notion of organizational culture. If one wants to retain the notion of culture (as a post-Cartesian notion) then it would best be describes at the background or horizon that renders certain dispositions possible and others not. The claim of this paper it that it is disposition (as attunement) that is of real importance in the implementation of information systems. As such, it has a substantial impact on the process of the adoption and diffusion of an information system. The discussion of this impact will first consider the perspectives of implementers and users before discussing how these actions subsequently lead to a restoration of a common feeling of sense.

\section{Implementers and Users}

Most organizational changes rely on the relative ability of some individuals or groups to impose their expectations on others (Berger and Luckmann 1966, p. 101). However, in the dialectic of control, most individuals or groups have a degree of power to influence the nature of change (Giddens 1984, p. 16). Any individual or group may present possibilities for change provided that they can form alliances and obtain control over the resources needed to achieve the required outcomes. Those without the power to propose changes still can accept or resist them (Frost and Egri 1991).

The process of change brought about by the adoption and diffusion of an information system can thus be viewed from two perspectives: that of "implementers"-not just the sub-group of designers, developers, and installers, but also those that support the system; and that of "users"- the subgroups that will use and be affected by the new system. The next section will commence the discussion of these perspectives with the strategies of implementers to present opportunities or new ways of doing things. 


\subsection{The Strategies of Implementers}

Implementers attempt to reveal things as doable, as making sense in the cohesive whole of the organization (Dreyfus 1991, p. 185). In this attempt, they use interpretations and assertions. Interpretations involve the uncovering of the cohesive world of the organization in order to appropriate the change. Assertions point out, elaborate and communicate the nature of the change (Dreyfus 1991, pp. 208-211). Often, implementers focus on the assertion of the value of the change such as the impact of information technology on the nature of purposeful activities. Less frequently, the focus will be on the interpretation of its impact on the underlying cultural structure. In so doing, implementers will draw on socialization methods and approaches, seek to change the reciprocities and balances of power in the ongoing conditions of work, and incorporate those methods and technologies which are approved or fashionable within their social networks.

Implementation strategies go beyond the specification, design or selection of the system and include the formation of alliances, obtaining control over the required resources, and preparing people, facilities, structures, and processes to accommodate the change. These strategies are elaborated in three categories derived from the work of DiMaggio and Powell (1983) and Fogarty (1992).

Organizations are modified by forces in their organizational field which result in them becoming more similar to one another, a process DiMaggio and Powell term isomorphism. They identify three mechanisms through which institutional isomorphic changes occur: coercive, mimetic and normative. Fogarty suggests that internal organizational socialization processes can be classified into three similar interacting and overlapping influences. These three isomorphic influences have, in turn, been adapted to arrive at three categories of implementation strategies.

\subsubsection{Coercive implementation strategies}

Coercive strategies are authoritarian, adversarial and imposed (Wastell and Newman 1996). They rely on the recognized authority and power of the implementers and the citing of rules and procedures. When the users have little opportunity to leave the organization, for example, when there is high unemployment, coercive strategies are more likely to be used. If the users have the possibility of mobility, and the proposed changes compare unfavorably with other organizations, implementers can place less reliance on a coercive approach.

Coercive strategies include technical training and indoctrination, direct supervision of the usage of the system, and reward for acceptable behavior. They can also use hidden inducements such as forcing those who refuse to use the system to produce the required information manually (Markus 1983).

\subsubsection{Mimetic implementation strategies}

Mimetic strategies occur when there is less clarity over who has the power to implement and when there is a necessity to build alliances in order to proceed. If implementers can 
persuade enough members to accept the system, actions and perspectives that are considered appropriate and desirable by the majority will be promoted. These strategies encourage members to adopt the change through the use of workshops, demonstrations and "ideological training," which emphasizes features valued by the users such as modernity and ease of use (Newman and Sabherwal 1996). These strategies are influenced by the perceptions the users have of similar systems in other organizations. Other techniques include mentoring and role modeling with the intention of getting the members to identify with and commit themselves to the new system.

\subsubsection{Normative implementation strategies}

As the users in a normative environment usually have a high level of power, it is likely that they will require considerable involvement in the entire adoption and diffusion process (El Sawy 1985). Normative strategies are designed to show that the system will contribute to the success of both users and the organization. Normative strategies include demonstrating that the system does not conflict with existing cultural values, standards and norms (El Sawy 1985). Other strategies include appeals to users to demonstrate their sense of loyalty and commitment (Frost and Egri 1991). When normative strategies are supported by the acceptance of respected peers, this can encourage acceptance of the system. However, senior managerial support is less important in this environment (Prescott and Conger 1995).

\subsubsection{The combination of implementation strategies}

The combination of the strategies used will be influenced by the implementers' levels of power or support and their degree of confidence, experience and skills (Frost and Egri 1991). The greater these are, the more likely that coercive strategies will be used. Strategies will also be influenced by the degree of change introduced by the system. The greater the change, the more resistance can be anticipated and the less likely coercive approaches will be used. In addition, each successive stage of the adoption and diffusion process is conditioned and influenced by previous events and actions (Walsham 1993, p. 57). Implementers will often be alert to this ongoing process and adapt their strategies accordingly.

Implementation strategies are not intended to overcome resistance but avoid it, if possible, and confront it constructively if not (Markus 1983). A key objective is to gain the support of users by fostering enthusiasm and commitment for the change rather than compliance (Senge 1990, p. 9). This requires an understanding of the possible reactions of users, the subject of the next section.

\subsection{The Reaction of Users}

The adoption and diffusion of an information system causes a form of breakdown-an upset to established ways of doing things. This breakdown brings to the fore the users' innate and historical dispositions, which are manifested as moods. As the members care 
whether the proposed change affects them and the achievement of their goals, they search for the reasons for the moods (Dreyfus 1991, pp. 175). Organizational disposition as a way of being opens up or discloses the impact of the change on the cohesive whole of the organization. The outcome of this is the reactions of users.

When the users can marshal sufficient power to resist a proposed system, their reactions remain primarily on the surface, involving detailed disclosure and explanation. The less the power of the users, the more likely that the strategies will be deep strategies, intense, political and sometimes irrational (Frost and Egri 1991). Reactions can thus vary in nature and intensity. These reactions will be discussed under three headings: rejection and failure, resistance and modification, and acceptance and commitment.

\subsubsection{Rejection and failure}

Reactions to a new information system can include treating the current ways of doing things as inviolate and thus ignoring or refusing to use the new system (Frost and Egri 1991). An alternative rejection approach is to ensure that the system does not function by deliberately using it incorrectly or ensuring that the output is incorrect and unusable (Myers 1994; Wastell and Newman 1996). Users may thus contend that they cannot use a system for technical reasons rather than disclose the true reasons for resistance (Markus and Keil 1994).

Users may be unhappy with the system but fear to directly resist the change. They may also not have sufficient power to reject the system. In this case, the reactions will attempt to modify the process.

\subsubsection{Resistance and modification}

Resistance and modification reactions are calculated to prevent the successful use of a portion of the system, or to customize the system to reflect the users' own requirements. Tactics include modifying the system to operate as if no change had occurred and keeping alternative sets of records (Markus 1983; Tyre and Orlikowski 1994).

Even when the users ostensibly accept the change, they may use subversive tactics to resist and modify. This can particularly apply when the implementation method has been coercive and the users feel anger at the way the change is implemented (Wastell and Newman 1996). Any resistance under these conditions will be likely to use informal power. Attempts will be made to build coalitions and gain support of other interest groups in order to collectively resist change (Frost and Egri 1991). At times, users will lack the collective organization to resist or they may be constrained by fear of reprisals (Clegg 1989, p. 220).

\subsubsection{Acceptance and commitment}

If the new system does not result in much change to activities and, in turn, to the norms, rules and meanings already institutionalized in the organization, there is a likelihood that users will accept and commit themselves to the system (Introna 1997, p. 134). 
Once the attempts to reject or resist and modify the system have been resolved or if there is substantial acceptance and commitment, the organization consolidates into a cohesive whole again. The next section will discuss the restoration of the common sense of the organization through a dialectic interaction between the interpretations and assertions of the implementers and the dispositions of the users manifested in reactions.

\subsection{Restoring the Common Sense of the Organization}

The diffusion of the information system into the ongoing everyday work of the organization will only be complete when the common sense of the organization is restored. This state is reached through an ongoing process which integrates and reconciles the users' and implementers' perspectives into a coherent whole. It may be that this coherent whole is quite unlike that anticipated by either the implementers or the users. Nevertheless, this, for the time being, will enable the organization to settle back into everyday activity. The process of restoring this common sense of the organization is illustrated in the framework developed below.

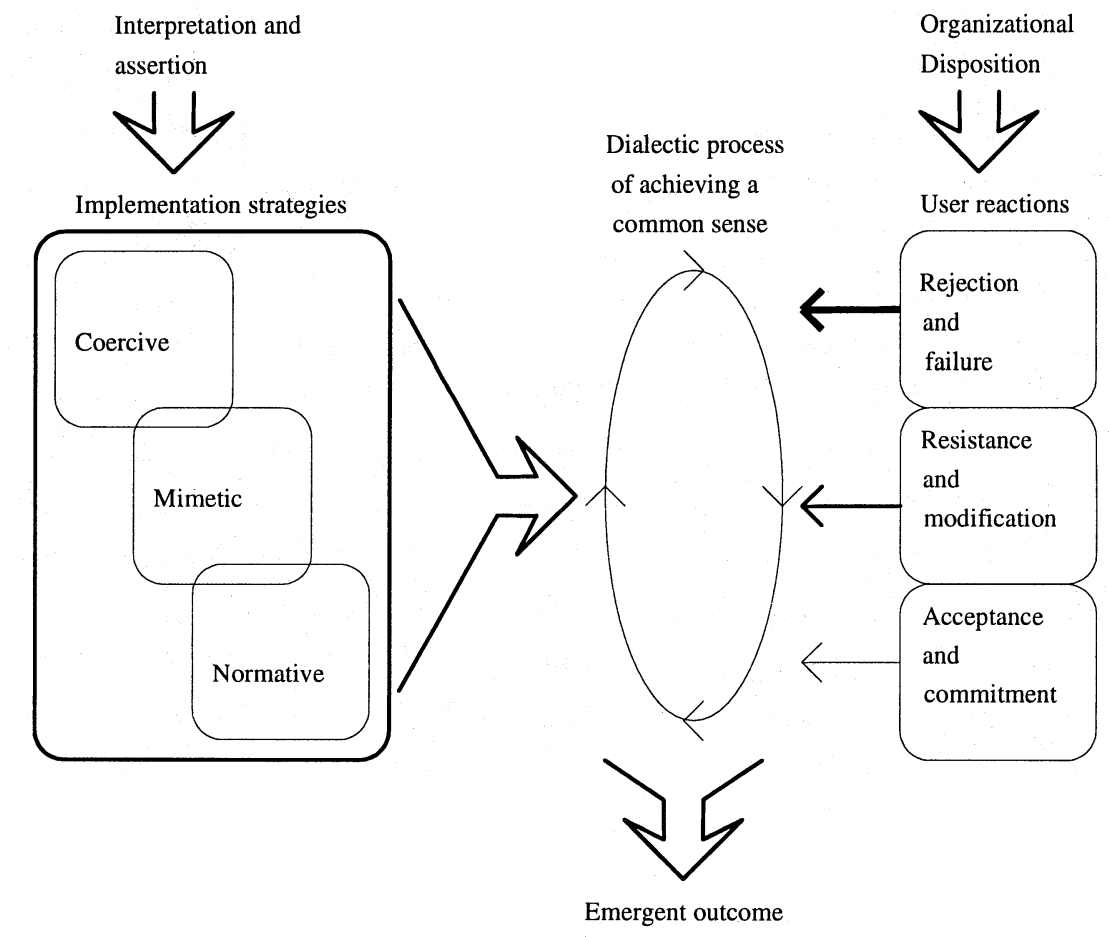

Figure 1. A Framework to Illustrate the Dialectic Process of Restoring the Common Sense of the Organization 
The historically based dispositions toward change trigger the evaluation of the possibilities presented by the implementers. Over time, users will attempt to manifest the reactions of rejection, resistance and modification, or acceptance and commitment, shown in Figure 1 as three possible user reactions which can influence the process of restoring the common sense of the organization.

Implementers' interpretations and assertions result in attempts to persuade and influence the users to accept the change. This is directed toward members re-evaluating their attitudes toward change and a reduction of resistance and confusion. If the implementation strategies fail, the system may have to be modified. The use of combinations of the implementation strategies are illustrated by the three overlapping strategies in the block on the left of Figure 1 and the arrow combining those strategies to influence the process of restoring the common sense of the organization.

There is a creative tension between what the implementers propose and the users' perception of what they want. This tension has been described as the dynamic equilibrium between holding on and letting go (Kofman and Senge 1995) or between persistence and change (Robey and Azevedo 1994). As Heidegger puts it: "One only is by directing oneself to a future on the basis of an existing past" (1962, p. (41)[20]). The resolution of this tension is illustrated by the circular dialectic process in the center of the framework.

As the adoption and diffusion process continues, efforts to restore the common sense of the organization need to adapt to ongoing events in the organization. There are often modifications to the system to overcome technical problems or to better achieve the outcome the system is required to produce. The users may experience a general distrust or lack of motivation engendered by other events in the organization. These factors could introduce a new set of reactions from the users. Consequently, the possible combinations of implementer strategies and user reactions are complex and the outcomes are not easy to predict even with the same information technology (Sahay and Robey 1996). It is thus not surprising that the change brought about by the introduction of an information system is not only emergent but seems to be messy and unpredictable (Coombs, Knights and Willmott 1992; Zuboff 1988, p. 395).

The process of adoption and diffusion of an information system is thus complex and recursive. Because of this, the research into the application of the framework needed to be interpretive. In this study, case studies were used as these provided rich insights into the dialectic process of restoring the common sense of the organization and adopting and diffusing information systems.

\section{Case Studies}

The following two case studies are intended to explain how the interaction of the implementers strategies and users reactions as illustrated in the framework result in an emergent outcome. These can thus be categorized as explanatory case studies (Yin 1994, p. 3). Of the two companies, one had rejected a proposed system while the other had achieved success with the adoption and diffusion of a large system. The two companies thus gave insights into different aspects of the adoption and diffusion process.

The case studies used a variety of sources of data in order to put together a rich text for interpretation. Personal observation over a period of more than two years, while 
consulting to the respective organisations, established the overall context. The principal source of data was interviews conducted as part of a larger project. Thirteen interviews were selected as being of particular relevance to this study. However, the remaining 23 interviews provided a rich background to those selected. The interviews were conducted over a period of eight months and the average duration was just over an hour. They were tape-recorded and verbatim transcripts produced.

The framework developed above guided the semi-structured research questions asked. However, although the purpose was to confirm and expand the theory, it was considered important to be open to alternative theoretical explanations of the answers received. Thus each interviewee was assured of confidentiality and encouraged to express his or her own views and recollections about the adoption and diffusion processes. The interviews were supported by documentation such as annual reports, strategic plans, implementation reports, slide presentations and training material so as to strengthen the development of the theory by the triangulation of evidence.

The resultant data was examined from two perspectives. First, the nature of the implementer strategies and user reactions was established. These strategies and reactions represented the tangible, first level understandings of the adoption and diffusion process. Underlying these first level understandings were the organizational dispositions of the respective organizations. This required a further analysis of the data to identify occurrences of common moods, how these opened up the cohesive whole of the organisation and found what mattered to the users, and finally how this contributed to restoring the common sense of the organization.

The final step in the analysis of the case studies is to seek patterns across both cases and to compare those patterns with existing or "enfolding" literature so as to improve the possibility of generalisation (Eisenhardt 1989).

\subsection{Bevco}

Bevco is a South African company that manufactures a single type of product under different brand names. It is divided into four geographic regions which are further divided into the functional areas of production, sales and distribution, and marketing. The system investigated in this study, referred to as Saturn, was considered, almost accepted and then rejected in favour of an alternative system.

\subsubsection{Implementation strategies}

The proposal to purchase Saturn was driven by a single manager. He adopted a predominantly mimetic strategy, which attempted to market his proposal on the basis of satisfying regional information requirements. His strategy included frequent consultations with colleagues and presentations to management of the benefits of the system. In the initial stages, he appeared to have support from a small group of head office managers. However, they tended to treat his proposal as a catalyst for general discussion about the information system needs of head office rather than those of the regions. Despite considerable effort for nearly a year, a final decision was not taken. His 
frustration at his inability to get the head office managers to commit themselves was reflected in his description of them as

herds of the lateral thinking, intellectual guys who want to participate in these energetic, frenzied debates but there are very few people who are disciplined enough to go back and say: "What were we debating, what did we learn, what do we actually need to do as the next step.

As it transpired, his approach failed, his support evaporated and he left the company.

\subsubsection{User reactions}

The main reactions to Saturn came from the finance group as it was having considerable difficulty in using its 27 incompatible legacy systems. When the financial director took over the information systems function, finance and information systems formed an alliance which set about putting forward two arguments to support their desire for better systems.

The first argument was that many of the financial systems were not year 2000 compliant. It was suggested that it was not practical to update the existing systems or to replace them with new systems compatible with Saturn. The proposal was to reject Saturn in favor of a system that would cater for the requirements of finance.

The second argument was the contention that the provision of financial information should be centralized in order to offer a better service. This was supported by a strategic need to buy raw materials centrally, a situation which had been signaled in the annual report. This need reinforced finance's argument as Saturn was unable to accommodate centralized procurement and finance systems.

An IS manager closely involved with the decision confirmed that, on the surface, these two reasons were accepted:

[W]e want to process our finance transactions centrally.... [and] we want centralized procurement information....Those two things on their own effectively canned our previous decision to buy [Saturn].

\subsubsection{Restoring the common sense of the organization}

The initial reactions to Saturn could be described as vague feelings that the proposal was not right. Initially, most of the managers interviewed reported a degree of discomfort with Saturn. These vague feelings and discomforts were to prove an important background to the process of restoring the common sense of the organization. It is informative to explore these further.

The manager proposing Saturn had a production background and had decided that the need was: "[To give] tools to shop floor processes to help them solve problems and to make decisions." This seemed to be a reasonable proposal as, over four years, a considerable degree of autonomy had been deliberately and carefully developed in the regions. This was intended to provide an environment where individuals and groups at 
all levels would be aware of and involved with Bevco strategies, be encouraged to translate those strategies into goals and to measure their progress toward the achievement of those goals. Saturn was to support this program by being installed at a regional level and being modified to suit local conditions. However, many head office managers felt that this autonomy had got out of hand and that a higher degree of centralisation was needed. This feeling was strongly expressed by the financial director:

\section{[M]y personal view is that people that tell shopfloor workers that they should be designing strategy are fools.... Strategy should be designed by people who can see further than a year ahead.}

This strongly worded statement pointed to a growing feeling, flowing from top management, that management information should be centrally provided. The managers were not always clear why this was needed and could only point to the need to buy raw materials centrally. This vague feeling was expressed by a manager of IS:

Let me say one thing....we must run this thing centrally because we want central information... we want to keep this stuff centrally because it is a core business requirement, we have got to do that.

This need had been influenced by a management consultancy which had suggested, among other things, that the company as a whole becomes the unit of analysis rather than the regions. The idea was to allocate the company's resources where they would be the most effective and to introduce a greater level of central planning.

Underlying the mood of resentment toward the freedom given to the regions and the mood of discomfort with the lack of centralized information was the aggressive nature of interactions in the head office. A head office manager described how this aspect of the culture became apparent as a result of the managers' search for reasons for their reluctance to accept Saturn:

[Bevco's] culture...may not be as chummy as it was in previous years. It is far more focused, far harder, far more business directed....It is highly individualistic and an internally very competitive culture.

As the implementing manager discovered, this had resulted in his proposal being subjected to intense scrutiny and discussion. This not only delayed the approval of the proposal and enabled resistance to develop, it also became acceptable to look for problems with Saturn.

A particularly strong feeling of resentment was expressed by the finance managers. They were upset that resources were being requested for a regional system when the existing financial systems were cumbersome and time consuming to operate. This mood provoked the finance managers into the realization that their conditions of work were unacceptable. This was a driver in their marshaling of acceptable reasons to justify their "resist and modify" reactions. This resulted in the finance group adopting the role of implementers and moving to the use of assertions. As the finance group was able to gain sufficient power to promote its needs ahead of those of the regions, they were able to reject Saturn in favor of an alternative system. 
The common sense that eventually emerged was a rejection of the system destined for the regions and the acceptance of an alternative system that was essentially financial. The regions were not very concerned about this as they had developed a cynicism as a result of the many proposals from head office that had failed to materialize. Saturn was merely another example. Head office managers saw the decision as further enhancement of their power as the outcome would be more centralized information and finance had gained an improvement in their conditions of work.

\subsection{Bankco}

Bankco specialized in banking for individuals and small businesses and had more than 200 outlets throughout South Africa. The system investigated in this study processed the transactions generated in these outlets, facilitated the interface between the customer and the bank, and collected the data needed to update the branch accounting system on the mainframe. It was an internally developed system, referred to as the branch delivery system or BDS.

\subsubsection{Implementation strategies}

The decision to adopt the BDS was confined to a small group of head office managers. At the early part of any project in Bankco, it was unusual to consult with users. This coercive approach was accepted and provoked little reaction. The initial installation of the BDS was into a pilot group of eight branches. Due to technical problems, strong reactions began to develop soon after the pilot implementation. As a result, an independent organization was commissioned to conduct a post pilot implementation study (PPIS) of the impact of the system. This was followed up by an internal review. The PPIS and the review confirmed that there was strong resistance to the system and that there were design and other problems.

The outcome was the withdrawal of part of the system and a change in the implementation approach. The implementers learned to listen to users, to acknowledge the design problems, and to change the system where needed. Slowly, the implementation approach changed to introduce a mimetic element into a still predominantly coercive strategy.

After some time, there was a recognition by the users that the system had been accepted by a major proportion of the staff. When this point of critical mass was reached, the implementation strategies became more coercive. While staff continued to be included in the upgrading and rewriting process, this was felt to be tokenism rather than true participation.

\subsubsection{User reactions}

Reactions will be discussed in three stages. The reactions to the pilot implementation; the reactions while implementation was ongoing; and the reactions after critical mass was achieved. 
The initial strong reactions. Technical problems, particularly poor response times, excessive down time, and an interface which made the system difficult to use, provoked requests to remove the new system and to revert to the previous one. There were particular objections to the impact of the system on the tellers. The staff said little at this stage. A branch manager in one of the pilot branches reported: "They were told: 'You will have the system and that's it'." However, the staff offered the PPIS a long list of minor faults. As they were unable to reject the system or even refuse to use the system, the only permissible official reaction was to find problems with the system.

As implementation proceeded, the initial strong resistance to the system waned. The users had gained what they saw as concessions. Part of the system had been removed, to some extent they were being listened to, and the system had been modified to work better. However, there were reactions to the ongoing implementation of the system.

Resistance to the ongoing implementation. As implementation proceeded, user reactions changed to "resist and modify." Many managers continued to use old manual systems such as the character cards, which were hand-written records of customer information including details of discussions with customers and any credit arrangements made. Several branch managers reported that the character cards had to be physically removed from the managers and filed away.

Due to inadequate training, staff tried to apply old procedures to the new system and did not use the functions that could make their work easier. Certain unusual transactions had not been included in the new system and the old system was left in place to conduct these. Staff discovered that the old system was still functional and then used whichever system suited their needs.

Critical mass and the subsequent reactions. "Critical mass" was reached when sufficient branches had been put onto the system to ensure that the others would accept the system in order to conform. At this point, users saw that the system could not be rejected so it made sense to cooperate. The reactions changed to acceptance, with minor resistance. The most usual reaction at this stage was that staff would only use a small range of functions essential to their work and would not explore possibilities.

\subsubsection{Restoring the common sense of the organization}

In the pilot implementation the system proved very difficult to work with and the managers soon became angry and resentful. The mood was such that normally compliant branch managers became outspoken. On several occasions the managers involved in the pilot implementation officially asked for the system to be taken out. As a manager put it: "[T]he guys put their foot down and [said], either take the system and shove it or let us get involved and talk to us before you make changes."

To some extent, this reaction was overdone. A branch manager at the time commented that: "There were a lot of things that were blown out of all proportion." Recollections of the events use terms such as "I was rude and dogmatic" and "I went berserk." This was unusual, as the managers were normally nervous to speak out about changes. A manager involved in the pilot implementation tells of an administrative manager who "had a good chirp" about the system and the next day phoned her manager to ask if she still had a job. 
It took some time for the reasons for these outbursts to be uncovered. One reason was a sense of distrust toward the implementers. One branch manager graphically described how action would only ever ensue (his language was more colorful) if the managing director came to hear of the problems. If he was unaware of the problems, nothing would happen.

The management also saw the BDS as causing significant changes, particularly to their conditions of work as the new system was very different from the old, both in its interface and in its scope. In addition, there were technical problems, particularly excessive down-time and poor response times. As a result, concern was being felt about the lengths of customer queues at the tellers and the impact of the technical problems on customer satisfaction. Thus there was an underlying sense that the system would introduce uncertainty way beyond that which the organization could cope with.

The normally compliant staff also reported feeling anger and resentment toward the pilot implementation of the BDS, even though they were unable to express this at the time. However, the suggestions offered to the consultants that conducted the PPIS reflected their feelings. For example, the tellers complained that they were suffering tiredness and eyestrain due to the difficulty of using the long and complex menus. In addition, the informal network was quick to spread what one interviewee referred to as "terrible stories" about the system.

The response of senior management to these reactions was initially one of surprise. In retrospect, a senior manager reflected: "I think we underestimated the initial resistance to change because it was just so different from the way in which we were doing it." The surprise of senior management provoked them into an unusual situation. They decided to formally investigate the problems. This, in turn, prompted a mood of discomfort for the implementers. A senior manager in head office described this situation: "The organization didn't like this report because we presented it up the line and it made people feel very twitchy and uncomfortable."

The combined effect of resentment and anger from the managers and staff and the discomfort of the implementers provoked an unusual situation for the bank, a complete change in the approach to implementing systems. As a senior head office manager commented, this was a "rude awakening." As a consequence, the cashier part of the system was removed, work was commenced on improving the response times and ease of use, and the implementation strategy was changed. These efforts were welcomed by the managers and staff. It resulted in a mood that conceived the system as a possibility that could be dealt with.

Tyre and Orlikowski (1994) refer to a relatively short window of opportunity during which the users adapt work techniques and practices to the information system and, at the same time, adapt the system to the existing techniques and practices. After this period, there is a consolidation and little further change takes place. This process of adaptation in Bankco was considerably longer than their experience. Ongoing upgrades considerably modified the system over a period of two to three years. During this period, the managers and staff had to adapt and readapt to these changes.

As a result, for some time there was an underlying resistance to change and a reluctance to accept the BDS. Many of the managers' and staff's reactions were accompanied by the feeling that the BDS had disturbed the comfortable flow of everyday work. A particularly strong reaction was from managers who were uncomfortable with 
the computerization of many of the manual aspects of their work. This reduced their feeling of control as there was not the comfort of a tangible document to work with.

Once the implementation of the system settled down into a routine of 10 to 15 branches a month, the mood in which they came to see themselves changed to a sensing of possibilities. Typical reactions that were reported were:

[In the beginning] everybody came, very deflated and they just said, ugh, another day, another day with the system. But if you look at it now, it is actually a pleasure coming to work.

It was, it was a bit scary because you...wonder [ed] now, gosh, are you going to be able to cope with your job now that it is all computerized. But as time goes by, you do, you learn... Now don't give me a job without a computer on my desk.

This change in mood was reinforced by transfers that took place in the bank. Managers and staff who had moved to branches without the BDS discovered that they preferred the new system and would say so. Managers or staff who still opposed the system were left with the options of leaving the bank or transferring to other divisions. Several took this option. There is now a high level of enthusiasm for the system and most would complain if the company reverted to the old system.

\section{Summary and Conclusions}

Research streams in the field of information systems implementation have, in the past, been rather narrow (Kwon and Zmud 1987). This study seeks to build on the work of Myers (1994) which illustrates that the adoption and diffusion of an information system is a hermeneutic process that can incorporate conflict and opposition often with unexpected results.

This study is based on the understanding that, within the cohesive whole of the organization, the members have a capacity or ability to be. There is thus always the possibility that members will find opportunities or new ways to do things as well as the possibility that members will have particular moods (disposition or attunements) as a result of confronting these opportunities or new ways to do things. As a consequence of these moods, there is a questioning of the disruption. Organization disposition is the way of disclosing what matters to the members in this change situation. This way contributes to a tacit awareness of the technologies, strategies and events surrounding the adoption and diffusion of an information system and, subsequently, to a restoration of a common feeling of sense.

The concept of organizational disposition was incorporated into an integrative framework that provided the theoretical background for two case studies. In both cases, the reactions of the users brought about a dialectic process in which the moods experienced enabled the opening up or uncovering of the reasons for resistance and opportunities for response. The findings supported the view of Myers that neither 
technology nor the strategies of implementers can be viewed as the sole drivers of change.

The initial reactions of users were not consciously thought out but rather manifested themselves in moods as a tacit awareness of the (in)appropriateness of the change. Subsequently, the users attempted to articulate the underlying "reasons" for those moods. Even then it was not a rational process in which all the impacts on the organisation as a whole were assessed. Users tended to monitor their situation and sought to sustain some meaningful whole, "something that makes sense." In Bankco, the managers initially sought to reject the system rather than experience the discomfort of what they perceived to be an inadequate system. In Bevco, the decision to implement was delayed while the reasons for the initial discomfort were opened up and explored. The outcome was of benefit to the finance group but did not address the need of the regions. This supported the view of Markus and Keil (1994) that even a functional system will be rejected if the users are not motivated by to use it as intended.

The restoration of the common sense of the two organizations was reached through an ongoing process that integrated and reconciled the users' and implementers' dispositions-flowing from their "being-in-it-ness" (Befindlichkeit)-into a new coherent whole. This was a dialectic process in which the mutual adaptation of the sense of the whole were made by both users and implementers, in the situation, as it emerged. This supported Markus (1983) contention that resistance is not a problem to be solved so that a system can be installed as intended.

As suggested by Dreyfus (1991), the context of significance and the cultural structure that make up the cohesive whole of the organisation provide the background that lends intelligibility to the criticism and change that arise from the adoption and diffusion process (p. 161). The adoption and diffusion process impacts on the context of significance through the modification of activities and introduction of new "equipment" and new expectations for action. It is the tacit awareness of the (im)possibilities in the situation that is the most significant. Clearly the cultural horizon will make certain possibilities come up and others not. However, what is significant for adoption and diffusion is the common sense of the possibility to be in the emerging context.

Robey and Azevedo (1994) point out that Schein's (1990) definition of culture suggests that it is something that an organization has. They suggest that this risks reducing culture to a set of independent variables. They conclude that researchers should rather seek an understanding of the process through which the information system can either reinforce or revise cultures. It is this paper's claim that the notion of organization disposition can facilitate this understanding.

Finally, this study demonstrated that the adoption and diffusion of an information system is a disruption that breaks down the cohesive whole of the organization. Organizational disposition provides a way to uncover the holistic web of meanings and understandings which enable the members to resolve conflicts and to restore the cohesive whole. This restoration does not imply that the system would be successfully implemented. It may be that rejection of the system is the outcome necessary to restore the common sense of the organization, dysfunctional as it may seem to the implementers.

While this study contributes to an understanding of the adoption and diffusion process, its general application is limited. The conclusions were based on a limited set of data within two organizations. In addition, other factors within the organizations may have contributed to the outcome. Despite this, it is contended that the main conclusions 
of this study have not been invalidated. However, further work is needed, particularly on the role of dialogue in disclosing the moods and assertions of the users and implementers.

\section{References}

Berger, P. L., and Luckmann, T. The Social Construction of Reality. Middlsex, England: Harmondsworth, Penguin Books, 1966.

Clegg, S. R. Frameworks of Power. London: Sage Publications, 1989.

Coombs, R.; Knights, D.; and Willmott, H. C. "Culture, Control and Competition: Towards a Conceptual Framework for the Study of Information Technology in Organizations," Organization Studies (13:1), 1992, pp. 51-72.

DiMaggio, P. J., and Powell, W. W. "The Iron Cage Revisited: Institutional Isomorphism and Collective Rationality in Organizational Fields," American Sociological Review (48), 1983, pp. 147-160.

Dreyfus, H. L. Being-in-the-world: A Commentary on Heidegger's Being and Time. Cambridge, MA: The MIT Press, 1991.

Eisenhardt, K. M. "Building Theories from Case Study Research," Academy of Management Review (14:4), 1989, pp. 532-550.

El Sawy, O. A. "Implementation by Cultural Infusion: An Approach for Managing the Introduction of Information Technologies,” MIS Quarterly, June 1985, pp. 131-140.

Fogarty, T. J. "Organizational Socialization in Accounting Firms: A Theoretical Framework and Agenda for Future Research," Accounting, Organizations and Society (17:2), 1992, pp. 129 149.

Frost, P. J., and Egri, C. P. "The Political Process of Innovation," in Research in Organizational Behaviour (Volume 13), L. L. Cummings and B. M. Staw (eds.). Greenwich, CT: JAI Press, 1991, pp. 229-295.

Giddens, A. The Constitution of Society, Cambridge, England: Polity Press, 1984.

Gouldner, A. W. "The Norm of Reciprocity: A Preliminary Statement," American Sociological Review (25:2), April 1960, pp. 161-178.

Haugeland, J. "Heidegger on Being a Person," Noûs (16:1), 1982, pp. 15-26.

Heidegger, M. Being and Time, tr. J. Macquarrie and E. Robinson. Oxford: Basil Blackwell Ltd, 1962.

Introna, L. D. Management, Information and Power. Hampshire, England: Macmillan, 1997.

Kofman, F., and Senge, P. "Communities of Commitments: The Heart of Learning Organizations," in Learning Organizations: Developing Cultures for Tomorrow's Workplace, S. Chawla and J. Renesch (eds.). Portland, OR: Productivity Press, 1995.

Kwon, T. H., and Zmud, R. W. "Unifying the Fragmented Models of Information Systems Implementation," in Critical Issues in Information Systems Research, R. J. Boland and R. Hirschheim (eds.). Chichester, England: John Wiley, 1987.

Markus, M. L. "Power, Politics and MIS Implementation," Communications of the ACM (26:6), 1983, pp. 430-444.

Markus, M. L., and Benjamin, R. I. "Change Agentry: The Next IS Frontier," MIS Quarterly, December 1996, pp. 385-480.

Markus, M. L., and Keil, M. "If We Build It, They Will Come: Designing Information Systems that People Want to Use," Sloan Management Review, Summer 1994, pp. 11-25.

Myers, M. D. "A Disaster for Everyone to See: An Interpretive Analysis of a Failed IS Project," Accounting, Management and Information Technology (4:4), 1994, pp. 185-201.

Newman, M., and Sabherwal, R. "Determinants of Commitments to Information Systems Development: A Longitudinal Investigation," MIS Quarterly, March 1996, pp. 23-54 
Pettigrew, A. M. "Context and Action in the Transformation of the Firm," Journal of Management Studies (24:6), November 1987, pp. 649-670

Prescott, M. B., and Conger, S. A. "Information Technology Innovations: A Classification by IT Locus of Impact and Research Approach," Data Base (26:2/3), 1995, pp. 20-41.

Robey, D., and Azevedo, A. "Cultural Analysis of the Organizational Consequences of Information Technology," Accounting, Management and Information Technology (4:1), 1994, pp. 23-37.

Sahay, S., and Robey, D. "Organizational Context, Social Interpretation, and the Implementation and Consequences of Geographic Information Systems," Accounting, Management and Information Technology (6:4), 1996, pp. 55-282.

Schein, E. H. "Organizational Culture," American Psychologist (45:2), 1990, pp. 109-119.

Senge, P. M. The Fifth Discipline. New York: Currency Doubleday, 1990.

Silverman, D. The Theory of Organizations. London: Heinemann, 1970.

Tyre, M. J., and Orlikowski, W. J. "Windows of Opportunity: Temporal Patterns of Technological Adaptation in Organizations," Organization Science (5:1), February 1994, pp. 98-118.

Van Maanen, J., and Schein, E. H. "Toward a Theory of Organizational Socialization," Research in Organizational Behavior, Volume 1, L. L. Cummings and B. M. Staw (eds.). Greenwich, CT: JAI Press, 1979, pp. 209-264.

Walsham, G. Interpreting Information Systems in Organisations. Chichester, England: J. Wiley and Sons, 1993.

Wastell, D., and Newman, M. "Information System Design, Stress and Organisational Change in the Ambulance Services: A Tale of Two Cities," Accounting, Management and Information Technology (6:4), 1996, pp. 283-300.

Yin, R. K. Case Study Research: Design and Methods, $2^{\text {nd }}$ ed. Thousand Oaks, CA: Sage Publications, 1994.

Zuboff, S. In the Age of the Smart Machine: The Future of Work and Power. New York: Basic Books, 1988.

\section{About the Author}

Brian O'Donovan is an Associate Professor at the University of the Witwatersrand and lectures in both information systems and management accounting. His Ph.D. drew on the philosophy of Heidegger to explore the dynamics of the adoption and diffusion of information systems in organizations. His current research interests and publication activities are concerned with the interaction between information systems and organizational change, strategic information systems, and control and performance measurement systems. 